\title{
Index autorum ad Vol. 16
}

Åkesson, H.O. 283

Adler, H. 103

Alström, C.H. Supplementum

Ard, E. 340

Arends, T. 162

Barker, J.P. 383

Basu, A. 184

Beckman, L. 59, 122, 223, 305, 362

Bell, W.N. 340

Bilbro, W.C., Jr. 265

Björling, G. 59, 122, 223, 305

Christodoulou, C. 59, 122, 223, 362

Cruz, M. 74 Das, S.R. 169 Datta, P. K. 89 Defrise-Gussenhoven, E. 198 Dronamraju, K. R. 258 Dutta, P.C. 95,327 Fessas, Ph. 362 Fusté, M. 371 Gallango, M.L. 162 Giles, CM. 155 Goedde, H.W. 350 Goodman, H.O. 132

396

Halvorsen, K. 231 Heiken, A. 155, 305 Henningsen, K. 239 Irizar, J.L. 371 Juel, E. 231

Kaltsoya, A. 362 King, J.S. 132 Kornstad, L. 231, 355 Lai, L.Y.C. 250,313 Larsen, A.M. Heier 355 Lindelius, R. Supplementum Linden, W. van der 377 Loesch, D. 321 Loukopoulos, D. 362 Mdzewski, B. 321 Mohr, J. 1 Mukherjee, D.P. 169 Murray, R.F. 113 Nichols, R.C. 265 Nilsson, L.-O. 362 Odom, J. 340 Ohligmacher, H. 350 Ørjasæter, H. 231, 355

Østgård, P. 231 Persson, I. 84 Planas, J. 371 Plato, Ch.C. 74 Prochnicka, B. 248 Pruzanski, W. 103 Renkonen, K.O. 276 Robinson, J.C. 113 Salzano, F.M. 242 Sastry, D.B. 169 Shreffler, D.C. 242 Thomas, J. J. 132 Thompson, J.C. 209 Thompson, R.B. 340 Tingsgård, P. 84 Vinas, J. 371 Visnich, S. 113 Walsh, R. J. 250 Weisert, O. 231 Westlin, N. 377 Whittaker, M. 209 Wolanski, N. 186 